Revista Tecné, Episteme y Didaxis: TED. Año 2014, Número Extraordinario. ISSN Impreso: 0121-3814, ISSN web: 2323-0126

Memorias, Sexto Congreso Internacional sobre Formación de Profesores de Ciencias. 08 al 10 de octubre de 2014, Bogotá

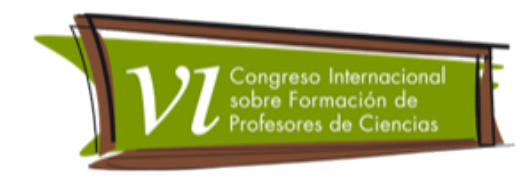

\title{
Os grupos de pesquisa em Educação Química e suas investigações sobre avaliação
}

Frozza Edson', Fantinelli Maiara², Pastoriza Bruno dos Santos³, Cacciamani Jackson Luis Martins ${ }^{4}$.

Categoria 2. Trabalhos de investigação

\section{Resumo}

Este trabalho traz as primeiras análises de uma investigação desenvolvida no Grupo de Pesquisa em Educação em Ciências Naturais (GPECieN) da Universidade Federal da Fronteira Sul (UFFS), Campus Realeza, Paraná, Brasil. Buscamos os grupos de pesquisa que abordavam em suas investigações a Educação Química e analisamos seus trabalhos publicados, atentando para as temáticas. Neste trabalho, dialogamos sobre as produções que trazem como foco a avaliação articulada ao desenvolvimento da Educação Química. A análise das produções ocorreu com base na análise textual discursiva (ATD) que possibilitou a criação de categorias a respeito das temáticas emergidas no transcorrer do tempo. Diagnosticamos que a avaliação é foco de discussão em poucos trabalhos e, isto implica em mencionar, que ainda não integra as investigações da maioria dos grupos de pesquisas em Educação Química.

\section{Palavras-chave}

Avaliação; Educação Química; Grupos de Pesquisa.

\section{Introdução}

Muito se tem produzido sobre Educação Química acerca de metodologias, de formação docente, de experimentação, dentre outros, por isso acreditamos ser importante compreender o processo de desenvolvimento da área de Educação Química e como esta tem contribuído na tarefa de ensinar e de aprender. Neste sentido, este trabalho traz elementos importantes que se entrelaçam com a formação de professores de Química no Brasil, como o sentido da pesquisa neste

\footnotetext{
1 Universidade Federal da Fronteira Sul (UFFS) - Brasil. Email: edsonfrozza@gpecien.com

2 Universidade Federal da Fronteira Sul (UFFS) - Brasil. Email: mfantinelli@gpecien.com

3 Universidade Federal da Fronteira Sul (UFFS) - Brasil. Email: pastoriza@gpecien.com

4 Universidade Federal da Fronteira Sul (UFFS) - Brasil. Email: cacciamani@gpecien.com
} 
Revista Tecné, Episteme y Didaxis: TED. Año 2014, Número Extraordinario. ISSN Impreso: 0121-3814, ISSN web: 2323-0126

Memorias, Sexto Congreso Internacional sobre Formación de Profesores de Ciencias. 08 al 10 de octubre de 2014, Bogotá

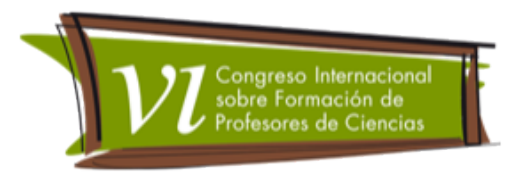

processo de reconhecimento dessa área a partir dos estudos realizados nela e acerca dela.

Este trabalho faz parte de uma investigação acerca dos grupos de pesquisa em Educação Química no Brasil desenvolvida pelo grupo de pesquisa em Educação em Ciências Naturais (GPECieN) da Universidade Federal da Fronteira Sul, Campus Realeza, Paraná, Brasil. Buscamos apresentar as principais tendências de discussões dos grupos constituídos entre 1982, ano de formação do grupo mais antigo encontrado, e 1995, ano de constituição da revista Química Nova na Escola, que transitam ou se inserem diretamente na área da Educação Química, em nível de Brasil, a partir dos trabalhos publicizados pelos integrantes dos grupos até o momento desta pesquisa. Dentre as várias possibilidades de caminhos a percorrer nesta pesquisa dialogamos sobre as investigações que trazem como foco a avaliação, buscando destacar a relevância desta no desenvolvimento da Educação Química.

Desde as décadas de 60 e 70 tem se falado sobre a avaliação, mas há uma necessidade em aprender a avaliar, conforme destaca Luckesi (2011). Nesse sentido, buscamos elencar os focos de discussão dessa área procurando identificar questões decorrentes da temática avaliação e do próprio ato de avaliar.

\section{Caminhos Metodológicos}

Buscamos os diferentes grupos que investigam acerca da Educação Química utilizando o Diretório dos Grupos de Pesquisa, vinculado à Plataforma Lattes, encontrando 128 grupos. Tendo em vista a proposta de analisar os trabalhos produzidos pelos grupos encontrados, optamos por um recorte que viabilizasse a análise. Nesse sentido, estabelecemos o período entre 1982, ano de criação do grupo mais antigo encontrado, e 1995, ano de constituição da revista Química Nova na Escola (QNEsC), momento importante onde surge um espaço voltado para os educadores, possibilitando a publicização de trabalhos que envolvem os processos de ensino e aprendizagem de química (BELTRAN et al.,1995). Do recorte estabelecido, encontramos 11 grupos a partir dos quais analisamos os trabalhos completos publicados em anais, artigos e livros, com base no Currículo Lattes dos pesquisadores até o presente momento.

Foram encontradas 1507 produções publicadas no período que vai desde o surgimento da área até o ano desta pesquisa. Como nosso objetivo é realizar um 
Revista Tecné, Episteme y Didaxis: TED. Año 2014, Número Extraordinario. ISSN Impreso: 0121-3814, ISSN web: 2323-0126

Memorias, Sexto Congreso Internacional sobre Formación de Profesores de Ciencias. 08 al 10 de octubre de 2014, Bogotá

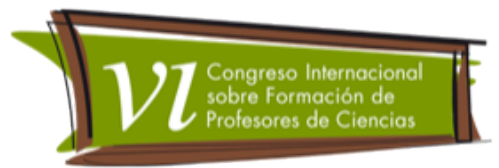

mapeamento inicial das temáticas investigadas na área da Educação Química, em primeiro momento realizamos uma análise exploratória integrada com a análise textual discursiva (ATD) (Moraes e Galiazzi, 2007) a partir dos títulos das produções selecionadas. A ATD se trata de um processo de análise que permite a partir de bases elementares destituídas de um texto orgânico, chamadas unidades de sentido, reconstruir o entendimento a respeito de determinado fenômeno ao aproximar estes elementos unitários por intermédio da categorização. Essa opção por realizar uma ATD a partir dos títulos dos trabalhos se embasa na concepção de que estes, em sua maioria, remetem ao foco ou às temáticas apresentadas no texto e essa análise possibilita realizar uma quantificação a partir das unidades de sentido.

Destacamos que, naqueles casos em que os títulos não possibilitavam a categorização do trabalho, buscamos os respectivos resumos no sentido de contribuir no processo de análise. Ressaltamos que no processo de unitarização cada trabalho emergiu uma ou mais unidades de sentido por entendermos que os títulos expressavam mais de uma ideia que poderiam estabelecer relações com as outras produções. Em um segundo momento, organizamos as unidades em categorias. Aqueles trabalhos que emergiram duas ou mais unidades podem estar contemplados em mais de uma categoria, as quais são apresentadas na tabela 1:

Tabela 1. Categorias e sua percentagem de distribuição entre os 1507 trabalhos $^{5}$

\begin{tabular}{|l|l|l|l|}
\hline $\begin{array}{l}\text { Aprendizagem } \\
5,2 \%\end{array}$ & $\begin{array}{l}\text { Avaliação } \\
0,9 \%\end{array}$ & $\begin{array}{l}\text { Cidadania } \\
5,0 \%\end{array}$ & $\begin{array}{l}\text { Coletividade } \\
2,9 \%\end{array}$ \\
\hline $\begin{array}{l}\text { Concepções } \\
4,9 \%\end{array}$ & $\begin{array}{l}\text { Cotidiano } \\
3,7 \%\end{array}$ & $\begin{array}{l}\text { Currículo } \\
10,3 \%\end{array}$ & $\begin{array}{l}\text { Educação Ambiental } \\
5,0 \%\end{array}$ \\
\hline $\begin{array}{l}\text { Ensino } \\
3,5 \%\end{array}$ & $\begin{array}{l}\text { Epistemologia } \\
1,7 \%\end{array}$ & $\begin{array}{l}\text { Estratégias de Ensino } \\
\text { e Aprendizagem } \\
23,0 \%\end{array}$ & $\begin{array}{l}\text { Formação Docente } \\
22,0 \%\end{array}$ \\
\hline $\begin{array}{l}\text { Linguagem } \\
11,8 \%\end{array}$ & Material didático $4,7 \%$ & $\begin{array}{l}\text { Percepções } \\
1,0 \%\end{array}$ & $\begin{array}{l}\text { Pesquisa } \\
7,0 \%\end{array}$ \\
\hline $\begin{array}{l}\text { Representações } \\
2,3 \%\end{array}$ & Saberes & $\begin{array}{l}\text { Situações Interativas } \\
5,4 \%\end{array}$ & $\begin{array}{l}\text { Tecnologias } \\
\text { Informação } \\
\text { Conhemunicação } \\
3,9 \%\end{array}$ \\
\hline
\end{tabular}

${ }^{5}$ Assumimos a possibilidade de um mesmo trabalho transitar em mais de uma categoria. 
Revista Tecné, Episteme y Didaxis: TED. Año 2014, Número Extraordinario. ISSN Impreso: 0121-3814, ISSN web: 2323-0126

Memorias, Sexto Congreso Internacional sobre Formación de Profesores de Ciencias. 08 al 10 de octubre de 2014, Bogotá

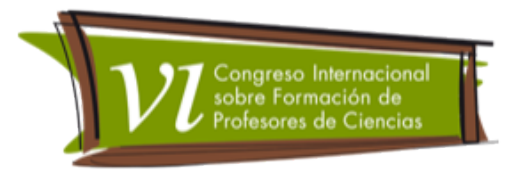

\begin{tabular}{|l|l|l|l|}
\hline $\begin{array}{l}\text { Interdisciplinaridade } \\
2,8 \%\end{array}$ & $\begin{array}{l}\text { Prática Docente } \\
6,3 \%\end{array}$ & $\begin{array}{l}\text { Educação Inclusiva } \\
1,0 \%\end{array}$ & $\begin{array}{l}\text { Conceitos } \\
9,7 \%\end{array}$ \\
\hline
\end{tabular}

Dentre as 24 categorias, a avaliação foi a que apresentou menor percentagem de trabalhos relacionados (0,9\%). Assim, compreendemos que merece ser mais discutida uma vez que trata de questões complexas que se articulam com o ensino e a aprendizagem, possibilitando repensar esses processos em sua totalidade. Ancoramos nosso argumento nas compreensões de que a avaliação "manifesta-se como um ato dinâmico que qualifica e subsidia o reencaminhamento da ação, possibilitando consequências no sentido da construção dos resultados que deseja" (Luckesi, 2011, p. 54) e ao entendermos que envolve a interação de diferentes sujeitos percebemos que a avaliação é um movimento participativo, de coletividade na problematização dos acontecimentos pertinentes (Demo, 2008). Com base nesses elementos buscaremos compreender quais temáticas têm delineado as pesquisas sobre os processos avaliativos a partir das produções analisadas.

A partir da ideia de que os processos avaliatórios no contexto da Educação Química perpassam ainda poucas produções dessa área, procedemos à leitura dos 7 trabalhos incluídos nessa categoria. Essa leitura buscou tanto um conhecimento da produção em si quanto a coerência à categoria criada, bem como um adensamento nas discussões que a área da Educação Química vem produzindo ao longo de sua história (compreendida pelos grupos incluídos em nosso recorte). Os trabalhos analisados foram:

Tabela 2. Trabalhos da categoria avaliação analisados 6

\begin{tabular}{|l|l|l|c|}
\hline & \multicolumn{1}{|c|}{ Título do trabalho } & Autores & Ano \\
\hline A & $\begin{array}{l}\text { Avaliação do livro didático e confecção de } \\
\text { materiais instrucional alternativos como estratégia } \\
\text { de formação continuada de professores }\end{array}$ & M. L. Eichler & 1998 \\
\hline B & $\begin{array}{l}\text { Avaliação de materiais didáticos produzidos de } \\
\text { forma integrada em atividades de formação } \\
\text { inicial e continuada de professores de Química }\end{array}$ & J. C. Del Pino & 2001 \\
\hline
\end{tabular}

\footnotetext{
${ }^{6} \mathrm{Na}$ tabela constam apenas os trabalhos encontrados.
} 
Revista Tecné, Episteme y Didaxis: TED. Año 2014, Número Extraordinario. ISSN Impreso: 0121-3814, ISSN web: 2323-0126

Memorias, Sexto Congreso Internacional sobre Formación de Profesores de Ciencias. 08 al 10 de octubre de 2014, Bogotá

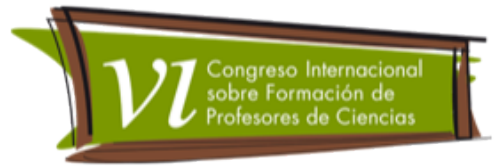

\begin{tabular}{|l|l|l|l|}
\hline & \multicolumn{1}{|c|}{ M. L. Eichler } & \\
\hline C & $\begin{array}{l}\text { Avaliação preliminar sobre o conceito de } \\
\text { radiação e algumas de suas tecnologias: idéias } \\
\text { informais de estudantes do ensino médio }\end{array}$ & E. F. Mortimer & 2007 \\
\hline D & $\begin{array}{l}\text { Mapa conceitual como estratégia para avaliação } \\
\text { da rede conceitual estabelecida pelos estudantes } \\
\text { sobre o tema átomo }\end{array}$ & J. C. Del Pino & P. Nunes \\
\hline E & $\begin{array}{l}\text { Check-list: um formulário para avaliação de } \\
\text { softwares educativos }\end{array}$ & E. P. Chacon & 2008 \\
\hline F & $\begin{array}{l}\text { Lessons from an educational game usability } \\
\text { evaluation }\end{array}$ & M. L. Eichler & 2012 \\
\hline A prova como instrumento de avaliação & C. R. C. da Silva & 2012 \\
\hline
\end{tabular}

\section{Análise e discussões}

\section{a. Panorama dos trabalhos}

Com o objetivo de discorrer mais acerca da avaliação fizemos leitura dos trabalhos dialogando sobre ela e sua importância nas pesquisas na área para o ensino e aprendizagem da Química, a partir das ideias propostas na ATD, que foram constituídas nessa historicidade das produções apresentadas em nosso recorte. 
Revista Tecné, Episteme y Didaxis: TED. Año 2014, Número Extraordinario. ISSN Impreso: 0121-3814, ISSN web: 2323-0126

Memorias, Sexto Congreso Internacional sobre Formación de Profesores de Ciencias. 08 al 10 de octubre de 2014, Bogotá

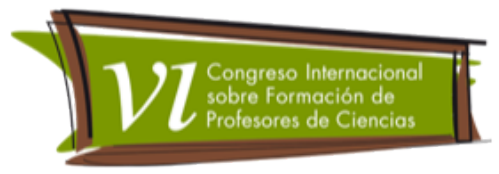

Sobre a análise podemos apontar que o trabalho A apresenta o desenvolvimento de atividades realizadas por um grupo de pesquisa na área da Educação Química com professores e licenciandos de Química, referentes à análise de livros didáticos e a confecção de materiais alternativos utilizando temas geradores. Tendo semelhante objetivo, os autores do trabalho B desenvolveram um projeto buscando estreitar as relações entre a Universidade e a Escola com objetivo de desenvolver materiais didáticos com os professores do Ensino Básico, partindo de temas geradores. O trabalho avalia a relação entre o material didático e o processo de ensinar e aprender, concluindo que a proposta é válida e que o tema gerador permite integrar vários conteúdos de química.

Já o trabalho $C$ discute sobre a importância de reconhecer as ideias informais do estudante e o papel delas nos processos de ensinar e aprender, apresentando resultados de uma avaliação que foi proposta com intuito de identificar as concepções prévias dos estudantes. $O$ trabalho $D$ apresenta uma análise sobre a utilização de mapas conceituais como estratégia de avaliação buscando verificar a capacidade dos alunos em relacionar os conceitos trabalhados. A atividade mostrou que os mapas conceituais podem levar o estudante a organizar e hierarquizar melhor os conceitos. Ainda sobre instrumentos de avaliação, o trabalho E discorre acerca do desenvolvimento de um modelo de avaliação (check-list) para jogos educacionais, buscando avaliar aspectos ergonômicos que se referem ao conforto e eficácia, e a aspectos pedagógicos, quanto ao aprendizado que ele proporciona. O check-list foi considerado uma ferramenta importante para auxiliar no desenvolvimento de jogos.

No trabalho $\mathrm{F}$, os autores utilizaram ferramentas, como questionário e vídeo, para avaliar um game educacional em desenvolvimento e verificar quais aspectos devem ser modificados ou melhorados. Em relação ao trabalho $G$ os autores investigaram, por meio de um questionário, qual a visão de professores e alunos do Ensino Básico quanto a avaliação do conhecimento na forma de prova escrita. Chegaram a conclusão que a prova escrita ainda é vista apenas como um instrumento classificatório, pra aferir nota, sendo que nenhum professor mencionou a prova como instrumento para avaliar seu trabalho.

\section{b. Análise sobre a avaliação nos grupos pertencentes ao recorte}

Atentando para as discussões, identificamos produções que buscam discutir a forma como é avaliado o conhecimento dos alunos. Os trabalhos demonstram em suas pesquisas diferentes concepções de avaliação, principalmente no que 
Revista Tecné, Episteme y Didaxis: TED. Año 2014, Número Extraordinario. ISSN Impreso: 0121-3814, ISSN web: 2323-0126

Memorias, Sexto Congreso Internacional sobre Formación de Profesores de Ciencias. 08 al 10 de octubre de 2014, Bogotá

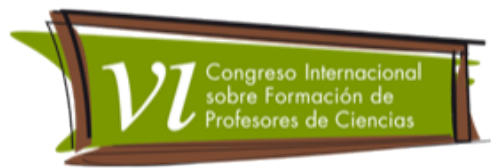

se refere a esta ser um processo constante ( $C$ e D), ou um momento pontual centrado unicamente no aluno $(G)$. Entendendo que o próprio ser humano está em contínua formação a avaliação deve partir desta concepção, e portanto, é um processo que traz elementos de movimento, temporalidade, dinamicidade, cooperatividade, entre outros (Luckesi, 2011 e Sant'Anna, 2011). Estes autores, assim como Libâneo (1994), Loch (2000) se preocupam em descentralizar o processo avaliativo apenas da figura do aluno.

Os trabalhos A, B, E e F trazem discussões sobre a avaliação de materiais didáticos, argumentando sobre a necessidade de avaliar a abordagem dos conceitos em livro didático, jogos, games, dentre outros. Nesse sentido Chacon et al. (2012, pág.3), menciona que "o computador e suas mídias são excelentes ferramentas no apoio às disciplinas do currículo acadêmico, porém se a usabilidade não for garantida todo o processo de ensino-aprendizagem estará comprometido". Diante das potencialidades que esses diversos materiais didáticos apresentam se faz necessária a avaliação de abordagens conceituais, sociais, culturais, éticas que venham a contribuir para sua melhoria e também para reencaminhar as estratégias de ensino.

Percebemos que o maior número dos trabalhos analisados enfoca a análise de materiais, não discutindo a avaliação em si. Isso mostra que a área da Educação Química se preocupou mais com estes aspectos do que com os básicos e teóricos do tema avaliação. Neste sentido, argumentamos que a necessidade de avaliar os distintos processos (ensino, aprendizagem, produção e desenvolvimento de materiais didáticos), assim como o próprio modo como avaliamos requer maiores espaço e tempo para diálogo e novos subsídios que intensifiquem os saberes acerca deste processo.

\section{Conclusão}

No decorrer desta pesquisa nos deparamos com o fato de que entre muitas produções, a avaliação, mesmo sendo fundamental no espaço escolar, não integra as investigações de grande parte dos grupos de pesquisas dessa área. Dessa forma, investigando a consolidação da Educação Química por meio de sua historicidade, com o foco em suas produções, vemos na avaliação uma área que ainda precisa de muitas pesquisas e ações que busquem e, no mínimo, problematizem maneiras mais coerentes/diversificadas/ainda não pensadas de avaliar e de teorizar acerca da avaliação. 
Revista Tecné, Episteme y Didaxis: TED. Año 2014, Número

Extraordinario. ISSN Impreso: 0121-3814, ISSN web: 2323-0126

Memorias, Sexto Congreso Internacional sobre Formación de Profesores de Ciencias. 08 al 10 de octubre de 2014, Bogotá

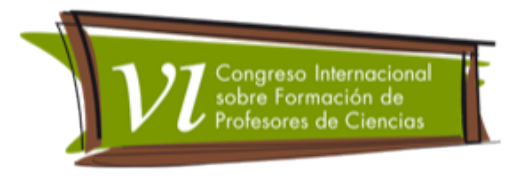

\section{Referências bibliográficas}

Beltran, N. O. (1995). Editorial Química Nova na Escola. Química Nova na Escola.

Chacon, E. P., Borges, M. N., Silva, C. R., \& Clua, E. (2012). Check-list: um formulário para avaliação de softwares educativos. Encontro Nacional de Ensino de Ciências da Saúde e do Ambiente. Niteroi.

Demo, P. (2008). Avaliação qualitativa. São Paulo: Autores associados.

Libâneo, J. C. (1994). Didática. Cortez.

Loch, J. M. (2000). Avaliação: uma perspectiva emancipatória. Química Nova na Escola, 30-33.

Luckesi, C. C. (2011). Avaliação da aprendizagem escolar: estudos e preposições. São Paulo: Cortez.

Moraes, R., \& Galiazzi, M. C. (2007). Análise textual discursiva. ljuí: Unijuí.

Sant'anna, I. M. (2011). Por que avaliar? Como avaliar? Critérios e instrumentos. Rio de Janeiro: Vozes. 